\title{
Risk factors and outcomes of diffuse alveolar haemorrhage after allogeneic haematopoietic stem cell transplantation
}

\author{
Jin Wu $\mathbb{D}^{1,2,3,4} \cdot$ Hai-Xia Fu ${ }^{1,2,3,4} \cdot$ Yun He ${ }^{1,2,3,4} \cdot$ Xiao-Dong Mo ${ }^{1,2,3,4} \cdot$ Xiao Liu' ${ }^{1,2,3,4} \cdot$ Xuan Cai ${ }^{1,2,3,4} \cdot$ Ruo-Yun Gui ${ }^{1,2,3,4}$. \\ Hui-Xin Liu ${ }^{5}$ Chen-Hua Yan ${ }^{1,2,3,4} \cdot$ Yu-Hong Chen ${ }^{1,2,3,4} \cdot$ Ying-Jun Chang ${ }^{1,2,3,4} \cdot$ Lan-Ping Xu ${ }^{1,2,3,4} \cdot$ Kai-Yan Liu ${ }^{1,2,3,4}$. \\ Xiao-Jun Huang ${ }^{1,2,3,4} \cdot$ Xiao-Hui Zhang $\mathbb{1}^{1,2,3,4}$
}

Received: 10 July 2020 / Revised: 15 March 2021 / Accepted: 29 March 2021 / Published online: 12 April 2021

(c) The Author(s), under exclusive licence to Springer Nature Limited 2021

\begin{abstract}
Diffuse alveolar haemorrhage (DAH) is a life-threatening pulmonary complication occurring after allogeneic haematopoietic stem cell transplantation (allo-HSCT) without an explicit aetiology or a standard treatment. This study aimed to explore the occurrence and prognosis of DAH after allo-HSCT, in addition to comparing discrepancies in the incidence, clinical characteristics and outcomes of DAH between patients undergoing haploidentical HSCT (HID-HSCT) and matched related donor HSCT (MRD-HSCT). We retrospectively evaluated 92 consecutive patients among 3987 patients with a confirmed diagnosis of DAH following allo-HSCT (HID: 71 patients, MRD: 21 patients). The incidence of DAH after allo-HSCT was $2.3 \%, 2.4 \%$ after HID-HSCT and $2.0 \%$ after MRD-HSCT $(P=0.501)$. The prognosis of patients with DAH after transplantation is extremely poor. The duration of DAH was 7.5 days (range, 1-48 days). The probabilities of overall survival (OS) were significantly different between patients with and without DAH within 2 years after transplantation $(P<0.001)$. According to the Cox regression analysis, a significant independent risk factor for the occurrence of DAH was delayed platelet engraftment $(P<0.001)$, and a high D-dimer level $(>500 \mathrm{ng} / \mathrm{ml})$ was a significant risk factor for the poor prognosis of DAH. HID-HSCT is similar to MRD-HSCT in terms of the outcomes of DAH.
\end{abstract}

\section{Introduction}

Allogeneic transplantation is widely accepted as a method for curing haematological malignancies. When matched related donors are not available, haploidentical donors provide

Supplementary information The online version contains supplementary material available at https://doi.org/10.1038/s41409021-01293-y.

Xiao-Hui Zhang

zhangxh100@sina.com

1 Peking University People's Hospital, Peking University Institute of Haematology, Beijing, China

2 Beijing Key Laboratory of Hematopoietic Stem Cell Transplantation, Beijing, China

3 Collaborative Innovation Centre of Haematology, Peking University, Beijing, China

4 National Clinical Research Centre for Hematologic Disease, Beijing, China

5 Peking University People's Hospital, Beijing, China patients with more opportunities for transplants. Recently, the efficacy and methods of haploidentical haematopoietic stem cell transplantation (HID-HSCT) have been gradually improved in many studies, and HID-HSCT has been suggested to be comparable to matched related donor HSCT (MRD-HSCT) in terms of the prognosis and outcome [1, 2].

As one of the pulmonary complications after HSCT, the incidence of DAH ranges from 3 to $8 \%$ [3-5]. DAH is defined as an acute onset of hypoxemia, dyspnoea and/or haemoptysis, while chest radiographs reveal new or aggravated diffuse pulmonary infiltrates, according to previous studies $[3,6,7]$. Previous studies have indicated that the presence of progressive bloody bronchoalveolar lavage (BAL) on bronchoscopy is one of the conditions for the diagnosis of DAH [6-9]. The pathological mechanism of DAH after bone marrow (BM) transplantation is unclear. According to previous studies, DAH may be related to the failure of neutrophil and platelet transplantation [3], direct or indirect damage to the lungs caused by acute graftversus-host disease (aGVHD) [7], infection [10], toxicity of the conditioning regimen [5] and the cytokine storm [11]. Despite the rapid administration of prophylactic antibiotics, 
systemic glucocorticoid therapy and supportive care, the mortality rate of DAH amounts to $80-100 \%[3,4,12]$. Consequently, the elucidation of the aetiology of DAH and effective treatment methods is urgently needed.

Previous studies of DAH have mainly focused on autologous HSCT and MRD-HSCT. To date, sufficient information showing the characteristics of DAH after HID-HSCT and comparing them with those after MRD-HSCT is unavailable. Therefore, we conducted a retrospective analysis to compare and document the incidence, risk factors and clinical outcomes of DAH in patients who underwent these two types of transplantation in our institution.

\section{Patients and methods}

\section{Patients}

This study adopted a retrospective nested case-control design. From July 2013 to January 2019, we identified 92 of 3987 consecutive patients (over 18 years old) who received allo-HSCT at the Institute of Haematology of Peking University for this study, including 2956 patients who underwent HID-HSCT and 1031 patients who underwent MRDHSCT. Patients who had been diagnosed with DAH following allo-HSCT were eligible (Fig. 1).

The rationale for matching patients and controls according to the time of transplantation and the length of follow-up not only ensured comparability of the two groups and reduced

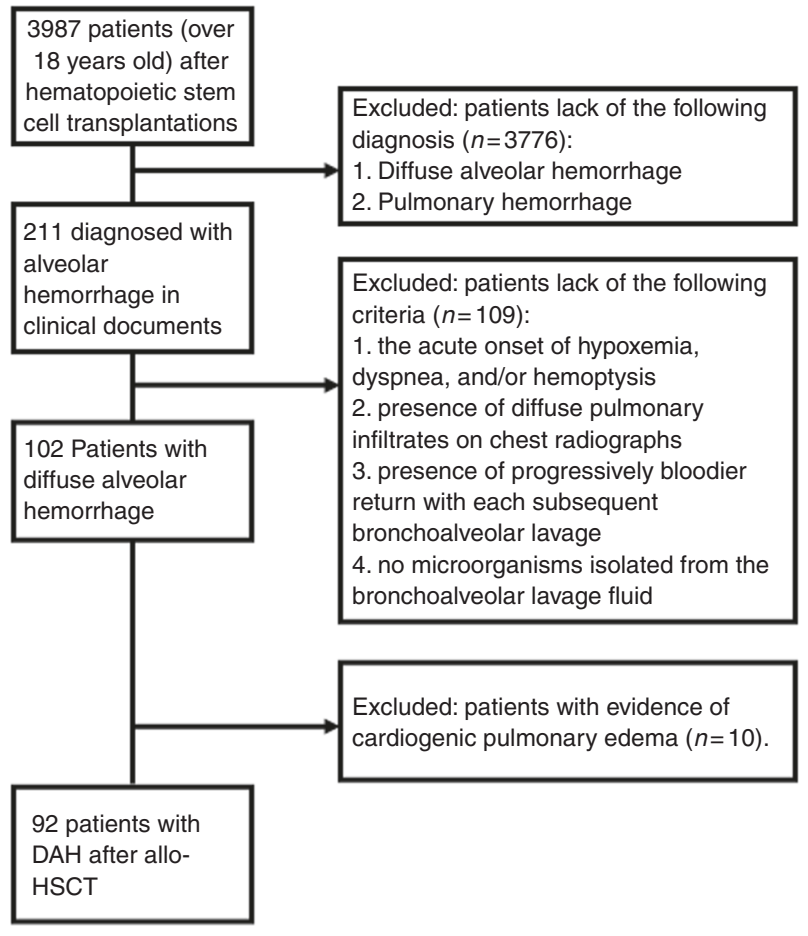

Fig. 1 Flow chart of patients included in the present analysis. confounding bias but also avoided overmatching. For each patient, we chose a control subject who was matched by the time of allo-HSCT $( \pm 1$ year) and the length of follow-up ( \pm 2 months). "The time of transplantation" referred to the day on which the patients received a stem cell infusion. Controls and patients were matched such that they would be comparable in terms of the details of HSCT and corresponding medical and nursing measures. "The length of follow-up" referred to the follow-up time after patients received a stem cell infusion. The two groups had comparative follow-up for researchers to observe the occurrence of DAH and other complications. Control subjects were selected from the same cohort by risk set sampling with SPSS version 25.0 software (International Business Machines Corporation. http://www. ibm.com/cn/) at a ratio of 1:3. For each selected control subject, we reviewed the medical records and confirmed that the patient did not have DAH. We identified 92 confirmed patients with DAH and 276 matched control subjects. The research project was approved by the Ethics Committee of Peking University People's Hospital and was performed in accordance with the Declaration of Helsinki.

\section{Transplantation procedure and GVHD prophylactic therapy}

Transplantation protocols developed by our institution have been presented in our previous reports [2, 13]. Patients treated with HID-HSCT received a regimen based on busulfan, including cytosine arabinoside (Ara-c, $4 \mathrm{~g} / \mathrm{m}^{2} / \mathrm{d}$, days -10 to -9$)$, busulfan $(\mathrm{Bu}, 3.2 \mathrm{mg} / \mathrm{kg} / \mathrm{d}$, days -8 to -6 ), cyclophosphamide (Cy, $1.8 \mathrm{~g} / \mathrm{m}^{2} / \mathrm{d}$, days -5 to -4 ), antithymocyte globulin (ATG, $2.5 \mathrm{mg} / \mathrm{kg} / \mathrm{d}$, days -5 to -2 ), simustine (Me-CCNU, $250 \mathrm{mg} / \mathrm{m}^{2} / \mathrm{d}$, day -3 ), or a regimen based on total body irradiation (TBI), including TBI (770 cGy, day -6), Cy $\left(1.8 \mathrm{~g} / \mathrm{m}^{2} / \mathrm{d}\right.$, days -5 and -4$)$, ATG (2.5 $\mathrm{mg} / \mathrm{kg} / \mathrm{d}$, rabbit, Sang Stat, Lyon, France, days -5 to -2 ) and $\mathrm{Me}-\mathrm{CCNU}\left(250 \mathrm{mg} / \mathrm{m}^{2} / \mathrm{d}\right.$, day -3$)$. Patients treated with MRD-HSCT received a regimen identical to the HID-HSCT recipients except that ATG was not administered. Granulocyte colony-stimulating factor (G-CSF, $5 \mu \mathrm{g} / \mathrm{kg} / \mathrm{d}$ ) was applied to mobilise BM cells and peripheral blood (PB) cells. All patients received an infusion of mobilised donor BM cells (harvested on day 4 after G-CSF) and PB cells (harvested on day 5 after G-GSF) [14]. Cyclosporine A, mycophenolate mofetil and short-term methotrexate were administered to all patients to prevent GVHD [13, 15].

\section{Definitions/diagnosis and treatment}

In our institute, bronchoalveolar lavage fluid was submitted for cytological and microbiological examinations. BAL fluid (BALF) samples were routinely subjected to the following tests: (1) Gram staining, fungal staining, Grocott-Gomori 
methenamine-silver staining, and acid-fast bacillus staining; (2) cytology examination; (3) bacterial and fungal culture; and (4) real-time polymerase chain reaction (PCR) and reverse transcription-PCR assays for the detection of atypical bacteria (e.g. Legionella species, Mycoplasma pneumoniae, and Chlamydia pneumoniae), herpesviruses (HSV types 1 and 2, Epstein-Barr virus [EBV], CMV, VZV, and human herpesvirus-6), respiratory viruses (respiratory syncytial virus, parainfluenovirus, influenza types $\mathrm{A}$ and $\mathrm{B}$, human metapneumovirus, human rhinoviruses, human coronaviruses [CoVs; OC43, 229E, NL63, and HKU1], and human bocavirus), polyomaviruses (BK virus and $\mathrm{JC}$ virus), adenovirus, parvovirus B19, norovirus, and enterovirus (coxsackie virus and enterovirus 71). The blood samples of patients with fever were submitted for the cytological and microbiological examinations mentioned above. In this study, DAH was defined as an acute onset of hypoxemia, dyspnoea, and/or haemoptysis with chest radiographs revealing new or aggravated diffuse pulmonary infiltrates [3, 6, 7]. The diagnosis of DAH was established based on the following criteria: (1) acute attack of hypoxemia, dyspnoea, and/or haemoptysis [3, 8-10]; (2) existence of diffuse pulmonary infiltration on chest radiographs $[4,6,7,16]$; (3) presence of progressively bloodier return with each subsequent bronchoalveolar lavage [4, 10, 17]; (4) no microorganisms isolated from the bronchoalveolar lavage fluid $[6,7]$; and (5) no evidence of cardiogenic pulmonary oedema detected by clinical manifestations, central venous pressure measurements, or echocardiography [9, 18]. The medical records of each patient were reviewed by a haematologist and a pulmonologist, ensuring that each patient included in the study met the diagnostic criteria for DAH.

In our article, we defined the endpoint of DAH in two situations. First, most of the patients in our article died from $\mathrm{DAH}$, and for these patients, the time when DAH ended was the time of death. Second, for those who recovered from DAH, the endpoint of DAH was defined as the complete resolution of haemoptysis and dyspnoea, progressive improvement and stabilisation of blood oxygen saturation without ventilator support and complete absorption of infiltration on CT. The duration of DAH is defined as the length of time between the onset and the end of the DAH.

All patients with DAH received supportive care, including oxygen support, maintenance of the fluid and electrolyte balance, supplementation of clotting factors or platelets, and the use of prophylactic or empirical antimicrobial agents. Treatment with high-dose corticosteroids usually started with an intravenous injection of $250 \mathrm{mg}$ to $2 \mathrm{~g}$ of methylprednisolone (MP) per day for the first 4-5 days and then the dose gradually decreased over the next 2-4 weeks. Patients were divided into two groups according to the average dose of MP administered for the initial 3 days: a low-dose group: $<10 \mathrm{mg} /$ $\mathrm{kg} /$ day, medium-dose group: $10-20 \mathrm{mg} / \mathrm{kg} / \mathrm{day}$, and highdose group: $\geq 20 \mathrm{mg} / \mathrm{kg} /$ day.
The day of stem cell infusion was defined as day 0. Platelet engraftment was defined as the first 7 consecutive days when the platelet count was $>20 \times 10^{9} / \mathrm{L}$ without transfusion, and neutrophil engraftment was defined as the first 3 consecutive days with $\mathrm{ANC}>0.5 \times 10^{9} / \mathrm{L}$. Relapse was categorised as haematological relapse, cytogenetic relapse or molecular relapse. Patients with acute leukaemia in the first or second complete remission phase, chronic myeloid leukaemia in the first chronic phase, myelodysplastic syndrome, and benign haematological diseases were classified as standard-risk patients. Other patients were considered high risk. aGVHD and cGVHD were diagnosed and graded according to previous criteria [19-22].

\section{Statistical analysis}

Demographic and transplant characteristics between groups were assessed using the Kruskal-Wallis test, and the $\chi^{2}$ test was used to determine the differences in categorical variables. Means and standard deviations are reported to summarise approximately normally distributed data, whereas medians and ranges are reported for skewed data. Variables with $P<0.2$ in the univariate Cox analysis were eligible for inclusion in the multivariate Cox regression analysis. Overall survival (OS) was estimated using the Kaplan-Meier method and compared using the log-rank test. A two-tailed $P<0.05$ was considered statistically significant. All statistical analyses were conducted with SPSS version 25.0 software (International Business Machines Corporation. http://www.ibm.com/cn/).

\section{Results}

\section{Demographic and transplant-related characteristics}

\section{Patients with and without DAH after allo-HSCT}

The overall incidence of DAH after allo-HSCT was $2.3 \%$. The demographic characteristics and relevant transplantation data for the patients who were included in this study are shown in Table 1 . The laboratory data were the latest test results obtained within 7 days before DAH onset (Supplementary Table 1). Among the initial symptoms of DAH, dyspnoea was most common and observed in $90.2 \%$ of patients with DAH, followed by haemoptysis in $45.7 \%$ of patients and fever in $29.3 \%$ of patients. The probability of haemoptysis occurring during the entire DAH course was $77.2 \%$.

\section{DAH in patients treated with MRD-HSCT or HID-HSCT}

No statistically significant differences in sex, distribution of underlying disease, interval from diagnosis to HSCT, disease 
Table 1 Baseline characteristics of patients following allo-HSCT.

\begin{tabular}{|c|c|c|c|c|c|c|}
\hline \multirow[t]{2}{*}{ Characteristics } & \multicolumn{4}{|l|}{ DAH } & \multirow[t]{2}{*}{ Non-DAH } & \multirow[t]{2}{*}{$P$ value } \\
\hline & Total & HID-HSCT & MRD-HSCT & $P$ value & & \\
\hline Number of patients & 92 & 71 & 21 & & 276 & \\
\hline Incidence & $2.3 \%$ & $2.4 \%$ & $2.0 \%$ & 0.501 & - & - \\
\hline \multicolumn{7}{|l|}{ Sex } \\
\hline Male & 64 & 48 & 16 & 0.592 & 163 & 0.083 \\
\hline Female & 28 & 23 & 5 & & 113 & \\
\hline Age median(range) & $36(18-57)$ & $33(18-57)$ & $45(18-57)$ & 0.003 & $36(18-61)$ & 0.614 \\
\hline Underling disease & & & & 0.727 & & 0.659 \\
\hline AL & 71 & 54 & 17 & & 218 & \\
\hline CML & 3 & 3 & 0 & & 13 & \\
\hline Others & 18 & 14 & 4 & & 45 & \\
\hline Disease risk & & & & 0.777 & & 0.540 \\
\hline Standard & 72 & 55 & 17 & & 226 & \\
\hline High & 20 & 16 & 4 & & 50 & \\
\hline Interval $^{\mathrm{a}}$ (days, range) & $234(41-4344)$ & $235(58-2648)$ & $234(41-4344)$ & 0.207 & $235(43-8276)$ & 0.185 \\
\hline Donor-Patient gender & & & & 0.218 & & 0.229 \\
\hline Identical & 51 & 42 & 9 & & 132 & \\
\hline Different & 41 & 29 & 12 & & 144 & \\
\hline ABO match & & & & 1.000 & & 0.631 \\
\hline Identical & 45 & 35 & 10 & & 144 & \\
\hline Different & 47 & 36 & 11 & & 132 & \\
\hline Conditioning regimen & & & & 0.191 & & 0.318 \\
\hline TBI based & 8 & 8 & 0 & & 15 & \\
\hline Chemotherapy-based & 84 & 63 & 21 & & 261 & \\
\hline \multicolumn{7}{|l|}{ Graft cell dose infused } \\
\hline $\begin{array}{l}\mathrm{MNC} * 10^{\wedge} 8 / \mathrm{kg}, \text { median } \\
\text { (range) }\end{array}$ & $8.255(5.40-13.11)$ & $8.14(5.40-13.11)$ & $7.66(5.94-11.12)$ & 0.297 & $7.935(3.76-13.81)$ & 0.379 \\
\hline $\begin{array}{l}\mathrm{CD} 34 * 10^{\wedge} 6 / \mathrm{kg}, \text { median } \\
\text { (range) }\end{array}$ & $2.78(0.27-8.20)$ & $2.61(0.27-8.20)$ & $1.67(0.56-4.05)$ & 0.254 & $2.34(0.28-7.4541)$ & 0.178 \\
\hline Stem cell source & & & & 0.796 & & 0.082 \\
\hline $\mathrm{BM}+\mathrm{PB}$ & 89 & 68 & 21 & & 275 & \\
\hline PB & 3 & 3 & 0 & & 1 & \\
\hline \multicolumn{7}{|l|}{ Post-transplant events } \\
\hline Neutrophil engraftment (n) & 92 & 71 & 21 & 1.000 & 276 & 1.000 \\
\hline Median days (range) & $16(9-27)$ & $16(9-27)$ & $16(10-23)$ & 0.144 & $14(8-33)$ & 0.160 \\
\hline Platelet engraftment & 64 & 48 & 16 & 0.592 & 232 & 0.004 \\
\hline Median days (range) & $15(9-73)$ & $21(9-73)$ & $16(9-38)$ & 0.744 & $15(7-135)$ & 0.137 \\
\hline III-IV Acute GVHD & 17 & 12 & 5 & 0.526 & 30 & 0.071 \\
\hline Extensive Chronic GVHD & 15 & 10 & 5 & 0.320 & 26 & 0.084 \\
\hline DLI & 31 & 24 & 7 & 1.000 & 88 & 0.797 \\
\hline Relapse & 9 & 8 & 1 & 0.459 & 43 & 0.226 \\
\hline Death & 84 & 64 & 20 & 0.677 & 112 & $<0.001$ \\
\hline $\begin{array}{l}\text { Follow-up, median } \\
\text { (range) (days) }\end{array}$ & $219(38-1847)$ & $184(38-1847)$ & $186(97-713)$ & 0.345 & $219(19-1853)$ & 0.237 \\
\hline $\begin{array}{l}\text { Median time to Dx after } \\
\text { transplantation (days, range) }\end{array}$ & $177(20-1157)$ & $135(20-1157)$ & $180(53-712)$ & 0.145 & - & - \\
\hline
\end{tabular}

allo-HSCT allogeneic haematopoietic stem cell transplantation, $D A H$ diffuse alveolar hemorrhage, $A L$ acute leukaemia, $C M L$ chronic myelogenous leukaemia, $B M$ bone marrow, $P B$ peripheral blood, $G V H D$ graft versus host disease, $M R D-H S C T$ matched related donor hematopoietic stem cell transplantation, HID-HSCT haploidentical donor hematopoietic stem cell transplantation, DLI Donor lymphocyte infusion, TBI total body Irradiation.

${ }^{a}$ Interval between the diagnosis of underlying diseases and transplantation.

status at the time of HSCT, donor-patient sex match, donorpatient $\mathrm{ABO}$ match, conditioning regimen, number of transplantations, stem cell source, graft cell dose infused, follow-up time, engraftment time and donor lymphocyte infusion were observed between the two groups. Patients in the HID group were younger than patients in the MRD cohort (Table 1).

\section{Risk factors for the occurrence of DAH}

The potential risk factors for DAH were analysed using a univariate analysis, as shown in Table 2 . Variables with $P<0.2$ between the two groups were evaluated using the multivariate Cox proportional hazard regression model 
Table 2 Risk factors for the occurrence of DAH in alloHSCT patients.

\begin{tabular}{|c|c|c|c|c|c|c|}
\hline \multirow[t]{2}{*}{ Risk factors } & \multicolumn{3}{|c|}{ Univariate } & \multicolumn{3}{|c|}{ Multivariate } \\
\hline & HR & $95 \% \mathrm{CI}$ & $P$ value & HR & $95 \% \mathrm{CI}$ & $P$ value \\
\hline Sex (male vs female) & 1.3 & $0.798-2.117$ & 0.293 & & & \\
\hline Age $(>35$ vs $\leq 35)$ & 1.062 & $0.705-1.600$ & 0.772 & & & \\
\hline Smoke (within 5 years) & 1.371 & $0.729-2.577$ & 0.328 & & & \\
\hline Disease status (high risk vs standard risk) & 1.287 & $0.784-2.114$ & 0.319 & & & \\
\hline HCT-CI ( $\geq 3$ vs $<3$ ) & 0.965 & $0.391-2.378$ & 0.938 & & & \\
\hline $\begin{array}{l}\text { Conditioning regimen } \\
\text { (TBI based vs Chemotherapy-based) }\end{array}$ & 1.915 & $0.925-3.966$ & $0.080^{*}$ & 1.380 & $0.627-3.038$ & 0.424 \\
\hline $\begin{array}{l}\text { Donor-patient gender } \\
\text { (mismatch vs match) }\end{array}$ & 0.836 & $0.554-1.262$ & 0.395 & & & \\
\hline ABO compatibility (mismatch vs match) & 1.132 & $0.752-1.705$ & 0.552 & & & \\
\hline HLA match (mismatch vs match) & 1.300 & $0.798-2.117$ & 0.293 & & & \\
\hline $\mathrm{CD} 34\left(\geq 2.27 * 10^{6} / \mathrm{L}\right.$ vs $\left.<2.27 * 10^{6} / \mathrm{L}\right)$ & 1.428 & $0.918-2.220$ & $0.114^{*}$ & 1.207 & $0.768-1.896$ & 0.415 \\
\hline DLI & 0.823 & $0.533-1.272$ & 0.381 & & & \\
\hline $\begin{array}{l}\text { Delayed neutrophil engraftment ( }>21 \\
\text { vs } \leq 21 \text { ) }\end{array}$ & 2.284 & $1.306-3.994$ & $0.004 *$ & 1.561 & $0.846-2.880$ & 0.154 \\
\hline $\begin{array}{l}\text { Delayed platelet engraftment }(>28 \\
\text { vs } \leq 28 \text { ) }\end{array}$ & 2.902 & $1.891-4.452$ & $<0.001^{*}$ & 2.759 & $1.761-4.323$ & $<0.001 * *$ \\
\hline Grade III-IV aGVHD & 1.693 & $0.999-2.869$ & $0.049^{*}$ & 1.468 & $0.818-2.633$ & 0.198 \\
\hline Extensive cGVHD & 1.089 & $0.626-1.896$ & 0.763 & & & \\
\hline Relapse & 0.651 & $0.327-1.297$ & 0.223 & & & \\
\hline $\mathrm{CMV}$ viremia & 1.079 & $0.710-1.639$ & 0.722 & & & \\
\hline EBV viremia & 1.147 & $0.648-2.033$ & 0.637 & & & \\
\hline
\end{tabular}

$D A H$ diffuse alveolar hemorrhage, $A L$ acute leukaemia, $C M L$ chronic myelogenous leukaemia, $B M$ bone marrow, $P B$ peripheral blood, GVHD graft versus host disease, $H L A$ human leucocyte antigen, $D L I$ Donor lymphocyte infusion, $T B I$ total body Irradiation, $H C T$-CI hematopoietic cell transplantation-specific comorbidity index, INR international normalised ratio, $C M V$ cytomegalovirus, $E B V$ Epstein Barr virus, $H R$ hazard ratio, $95 \%$ CI 95\% confidence interval.

$* p<0.2$ in univariate analysis; $* * p<0.05$ in multivariate analysis. to predict the independent risk factors for DAH after HSCT. Among these variables, the difference in delayed platelet engraftment ( $>28$ days) remained significant and was considered an independent risk factor for DAH (Table 2).

\section{Treatment and outcomes of DAH following allo- HSCT}

The prognosis of patients with DAH after transplantation is extremely poor. Overall, 77 patients $(83.4 \%), 83$ patients $(90.2 \%), 84$ patients $(91.3 \%)$ and 84 patients $(91.3 \%)$ died within 30 days, 60 days, 100 days and 1777 days (the final follow-up after the diagnosis of DAH), respectively, from the onset of alveolar haemorrhage (Supplementary Table 2). The duration of DAH was 7.5 days (range, 1-48 days). The probabilities of OS were significantly different between patients with and without DAH within 2 years after transplantation ( $11.96 \%$ vs $59.78 \%$, respectively, $P<0.001$, Fig. 2 a). Regardless of which source of transplantation was adopted, the OS of patients with DAH was significantly lower than patients without DAH $(11.96 \%$ vs $59.78 \%$, respectively, $P<0.001$, Fig. $2 \mathrm{~b} ; 4.76 \%$ vs $73.91 \%$, respectively, $P<0.001$, Fig. $2 \mathrm{c})$. A significant difference in the probabilities of 100-day OS was not observed between the HID-DAH and MRD-DAH groups (14.08\% vs $4.76 \%$, respectively, $P=0.660$, Fig. 2 d).

Sixty-two patients were treated in the ICU. All patients received glucocorticoid treatment, 14 of whom received low-dose treatment, 54 of whom received medium doses, and 24 of whom received high-dose treatment. The 100-day survival rate from the onset of alveolar haemorrhage was $25.93 \%$ for patients who received medium-dose MP, compared with $7.14 \%$ for those who received low-dose MP $(P=0.085)$ and $0 \%$ for those who received high-dose MP $(P=0.029)$ (Fig. 3a). No significant differences in OS were observed in patients receiving glucocorticoid treatment at the same level between groups with different transplant sources (HID and MRD) (Fig. 3b).

Forty-five patients needed tracheal intubation, while 29 people required noninvasive ventilators. In terms of OS, no difference was observed in the need for or lack of intubation 

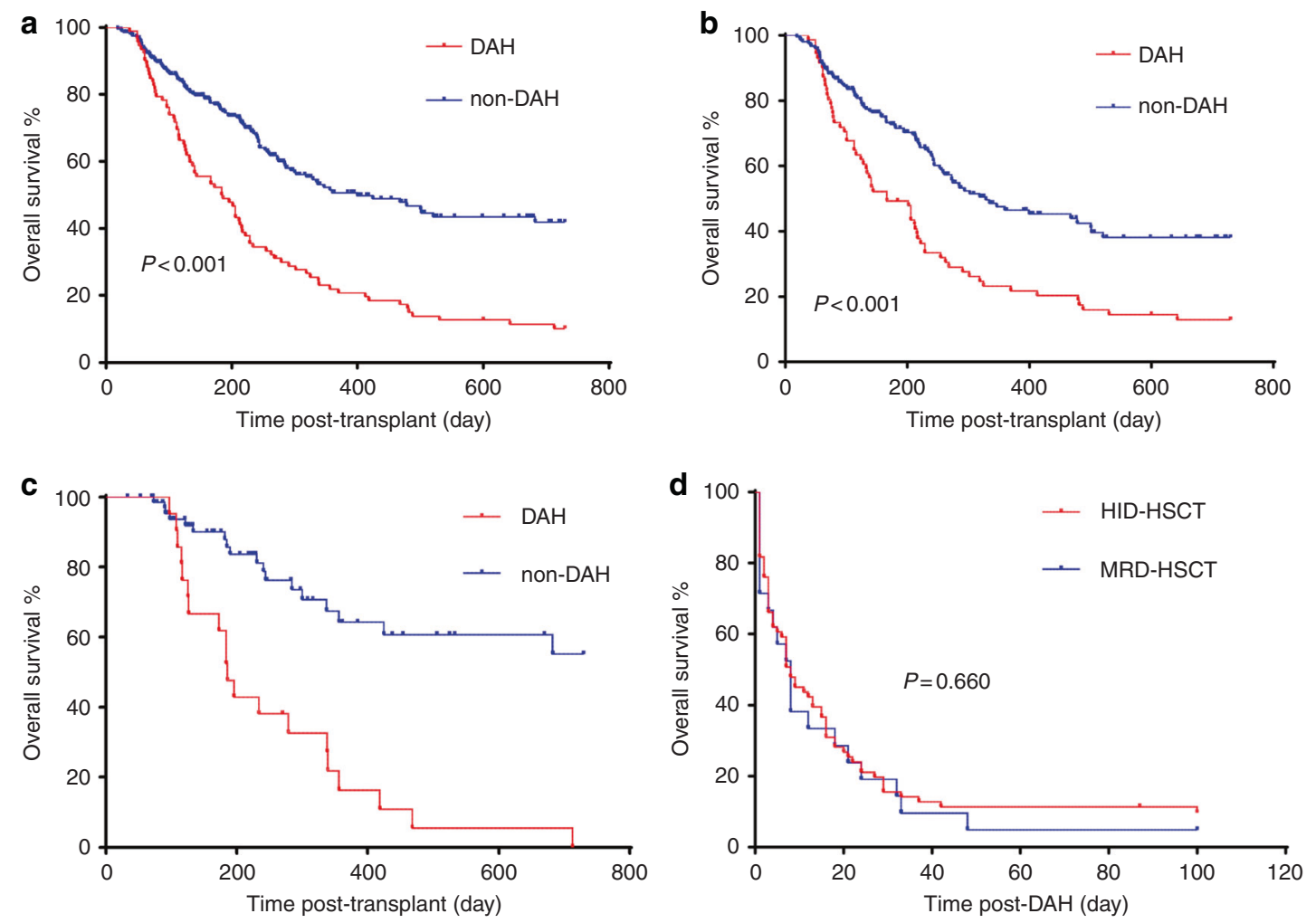

Fig. 2 Comparison of overall survival following allo-HSCT. a Patients with DAH and controls following allo-HSCT; b Patients with DAH and controls following HID-HSCT; c Patients with DAH and

controls following MRD-HSCT; d Patients with DAH following MRD-HSCT or HID-HSCT.
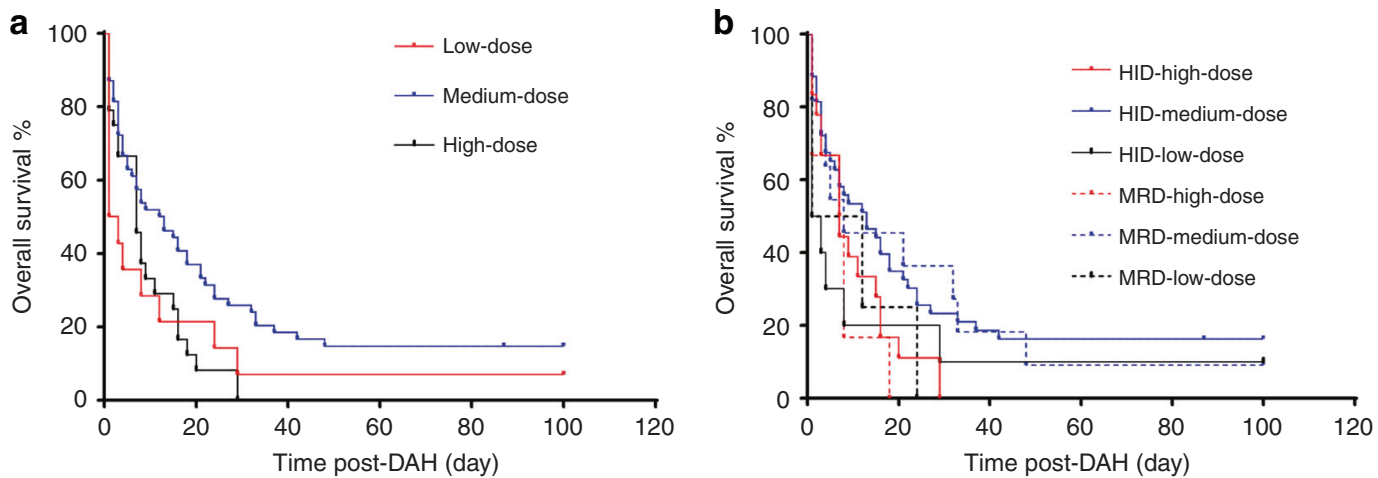

Fig. 3 OS of patients with DAH treated with different doses of glucocorticoid. a Patients with DAH following allo-HSCT; b Patients with DAH following HID-HSCT and MRD-HSCT.

between patients with DAH $(2.22 \%$ vs $14.89 \%$, respectively, $P=0.061$, Fig. 4a). The application of noninvasive ventilators did not affect the prognosis of patients with DAH $(P=0.981)$. Moreover, for the two oxygen supply therapies, the HID-HSCT and MRD-HSCT recipients exhibited similar OS rates (Fig. 4b). Coagulation factor VIIa was administered to 3 patients, and tranexamic acid was administered 2 patients. These patients died at 3, 6, 22, 28 and 31 days after the onset of DAH.

\section{Characteristics and outcomes related to glucocorticoid dosing}

According to the different doses of steroids used, the patients were divided into three groups: low-dose, mediumdose and high-dose groups. Supplementary Table 3 lists the laboratory data collected at the onset of DAH and the treatment of mechanical ventilation. Significant differences in baseline characteristics or mechanical ventilation 

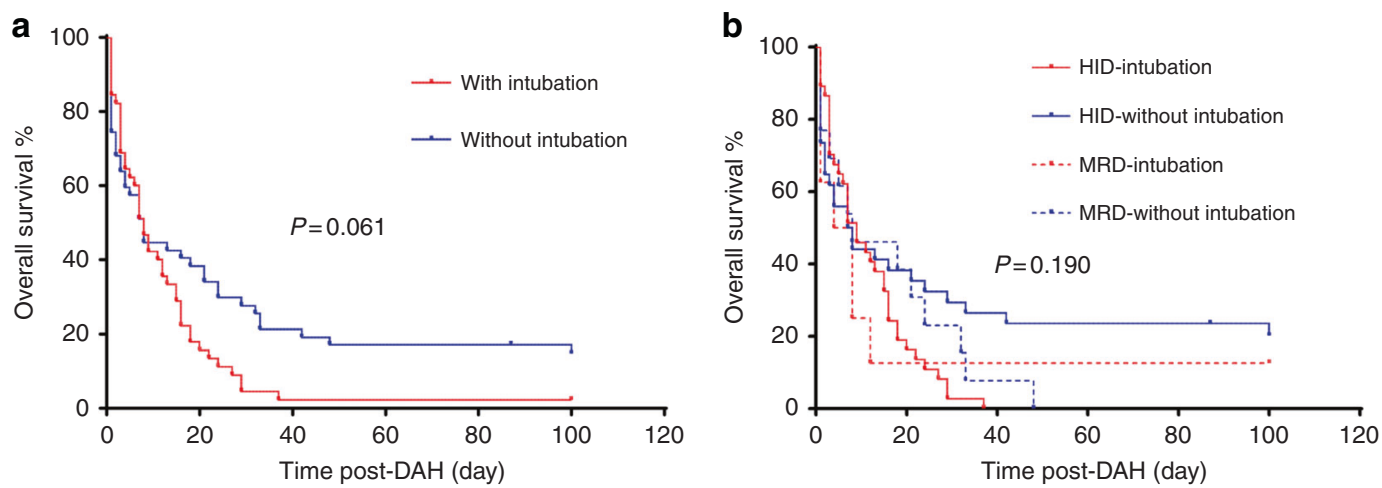

Fig. 4 OS of patients with DAH treated with/without intubation. a Patients with DAH following allo-HSCT; b Patients with DAH following HID-HSCT and MRD-HSCT.

treatment were not observed among the three groups. Compared with the low-dose $(92.86 \%)$ and high-dose $(0)$ groups, the 30-day mortality rate of patients receiving moderate-dose steroids was lower (74.07\%) $(P=0.009$, Supplementary Table 3). No significant differences were found in 60-day or 100-day mortality.

\section{Prognostic factors for DAH}

We conducted univariate and multivariate analyses to determine the factors contributing to a poor prognosis of DAH (Table 3). Platelet counts were transformed into a dichotomous variable with a cut-off of $20 \times 10^{9} / \mathrm{L}$. Hb levels had a cut-off of $60 \mathrm{~g} / \mathrm{L}$. The INR had a cut-off of 1.5 . D-dimer values had a cut-off of $500 \mathrm{ng} / \mathrm{ml}$. Fibrinogen levels had a cutoff of $2 \mathrm{~g} / \mathrm{L}$. The D-dimer level (>500 $\mathrm{ng} / \mathrm{ml})$ was strongly associated with a poor clinical outcome of DAH (Table 3).

\section{Discussion}

In recent years, DAH has received increasing attention as a complication after allogeneic haematopoietic stem cell transplantation. However, few studies have reported the results of DAH after HID-HSCT and compared them with the results after MRD-HSCT. Here, our results indicate a similar incidence of DAH in patients receiving MRD-HSCT to that in patients receiving HID-HSCT. In addition, DAH is an important complication of both HID-HSCT and MRDHSCT with an extremely poor prognosis.

The incidence of DAH in HSCT recipients ranges from 3 to $8 \%$, according to previous reports [23]. In the study by Kekre [3], the authors classified all patients as having DAH, regardless of a documented infection from bronchoalveolar lavage. Our study excluded all patients in whom microorganisms were detected in the BALF. The incidence, risk factors, and prognosis were calculated based on patients with diffuse alveolar haemorrhage without microorganisms in the BALF. In our study, the cumulative incidence of DAH was $2.3 \%$. The type of transplantation did not affect the incidence of DAH. Due to the lack of effective treatment strategies for DAH, the current method to improve the prognosis is to identify as many risk factors as possible and avoid their occurrence.

Among the initial symptoms of DAH, dyspnoea, haemoptysis and fever are the most common. Although none of the patients with DAH in our study were diagnosed with an infection, patients with fever still accounted for $29.3 \%$, which is not significantly different from the proportion of patients with fever reported in the literature [5, 6, 16, 24]. This lack of difference may be due to inflammatory processes with neutrophil infiltration through the endothelial wall into the lung parenchyma [3, 25], chemotherapyinduced mucositis [26] and other factors. In the multivariate analysis reported by SW Um, bleeding was identified as a risk factor for fever [27]. The mechanism of fever caused by bleeding is not very clear, and this mechanism may also be related to systemic and pulmonary inflammation evoked by haemorrhage [27-29]. Haem and other haemoglobin byproducts may function as ligands for Toll-like receptor 4 (TLR4), and TLR4 stimulation occurs first peripherally along with the recruitment of circulating macrophages and neutrophils and peripheral endothelial cells (EC) that produce PGE2, which leads to fever [30-32].

We identified delayed platelet engraftment was an independent significant risk factor for DAH. Delayed platelet engraftment was also considered a risk factor for DAH in the study by Keklik [3]. Delayed platelet engraftment indicates long-term thrombocytopenia, which makes patients prone to bleeding. Although thrombocytopenia clearly leads to an increased risk of haemorrhagic disease after haematopoietic stem cell transplantation, platelet supplementation does not effectively alleviate the progression of DAH $[3,33,34]$. The duration of platelet deficiency, but 
Table 3 Prognostic factors of DAH in allo-HSCT patients.

\begin{tabular}{|c|c|c|c|c|c|c|}
\hline \multirow[t]{2}{*}{ Risk factors } & \multicolumn{3}{|c|}{ Univariate } & \multicolumn{3}{|c|}{ Multivariate } \\
\hline & HR & $95 \% \mathrm{CI}$ & $P$ value & HR & $95 \% \mathrm{CI}$ & $P$ value \\
\hline Sex(male vs female) & 1.094 & $0.688-1.740$ & 0.704 & & & \\
\hline $\operatorname{Age}(>35$ vs $\leq 35)$ & 1.183 & $0.770-1.818$ & 0.443 & & & \\
\hline Disease status (high risk vs standard risk) & 1.294 & $0.766-2.188$ & 0.335 & & & \\
\hline $\begin{array}{l}\text { Conditioning regimen } \\
\text { (TBI based vs Chemotherapy-based) }\end{array}$ & 1.537 & $0.735-3.212$ & 0.253 & & & \\
\hline HLA match (mismatch vs match) & 1.113 & $0.673-1.840$ & 0.676 & & & \\
\hline $\begin{array}{l}\text { Delayed neutrophil engraftment (>21 } \\
\text { vs } \leq 21 \text { ) }\end{array}$ & 0.892 & $0.501-1.587$ & 0.697 & & & \\
\hline Delayed platelet engraftment ( $>28$ vs $\leq 28$ ) & 1.379 & $0.894-2.128$ & $0.146^{*}$ & 1.013 & $0.618-1.661$ & 0.958 \\
\hline Grade III-IV aGVHD & 1.487 & $0.878-2.516$ & $0.140 *$ & 1.241 & $0.679-2.262$ & 0.484 \\
\hline Extensive cGVHD & 1.393 & $0.769-2.525$ & 0.274 & & & \\
\hline Relapse & 1.653 & $0.819-3.338$ & $0.161^{*}$ & 1.351 & $0.629-2.899$ & 0.440 \\
\hline Platelet ( $<20$ vs $\left.\geq 20^{*} 10^{\wedge} 9 / \mathrm{L}\right)$ & 1.400 & $0.903-2.171$ & $0.133^{*}$ & 1.350 & $0.850-2.146$ & 0.204 \\
\hline $\mathrm{Hb}(<60$ vs $\geq 60 \mathrm{~g} / \mathrm{L})$ & 0.760 & $0.379-1.521$ & 0.438 & & & \\
\hline INR ( $\geq 1.5$ vs $<1.5)$ & 1.282 & $0.694-2.368$ & 0.428 & & & \\
\hline D-dimer ( $\geq 500$ vs $<500 \mu \mathrm{g} / \mathrm{L}$ ) & 2.559 & $1.436-4.559$ & $0.001 *$ & 2.557 & $1.426-4.584$ & $0.002 * *$ \\
\hline Fibrinogen $(<2$ vs $\geq 2 \mathrm{~g} / \mathrm{L})$ & 1.122 & $0.694-1.813$ & 0.639 & & & \\
\hline $\mathrm{CMV}$ viremia & 0.973 & $0.630-1.503$ & 0.902 & & & \\
\hline EBV viremia & 0.766 & $0.414-1.415$ & 0.394 & & & \\
\hline \multicolumn{7}{|l|}{ Glucocorticoid } \\
\hline Low & 1 & & & & & \\
\hline Medium & 0.581 & $0.313-1.079$ & $0.085^{*}$ & 0.552 & $0.275-1.110$ & 0.096 \\
\hline High & 1.026 & $0.518-2.029$ & 0.942 & 0.874 & $0.392-1.948$ & 0.741 \\
\hline \multicolumn{7}{|l|}{ Mechanical ventilator } \\
\hline Intubation & 1.530 & $0.981-2.388$ & $0.061^{*}$ & 1.401 & $0.837-2.342$ & 0.200 \\
\hline noninvasive ventilation & 0.995 & $0.631-1.567$ & 0.981 & & & \\
\hline $\operatorname{Scr}(\geq 90$ vs $<90 \mathrm{umol} / \mathrm{L})$ & 0.619 & $0.250-1.534$ & 0.300 & & & \\
\hline eGFR (<90 vs $\geq 90 \mathrm{~mL} / \mathrm{min} / 1.73 \mathrm{~m} 2)$ & 2.327 & $0.346-4.178$ & 0.320 & & & \\
\hline \multicolumn{7}{|l|}{ LDH (U/L) } \\
\hline$<245$ & 1 & & & & & \\
\hline$\geq 245$ & 1.547 & $0.800-2.991$ & 0.211 & & & \\
\hline$\geq 490$ & 0.918 & $0.512-1.647$ & 0.775 & & & \\
\hline Proteinuria (positive vs negative) & 1.096 & $0.594-2.020$ & 0.770 & & & \\
\hline
\end{tabular}

HID-HSCT haploidentical donor hematopoietic stem cell transplantation, $D A H$ diffuse alveolar hemorrhage, $A L$ acute leukaemia, $C M L$ chronic myelogenous leukaemia, $B M$ bone marrow, $P B$ peripheral blood, $G V H D$ graft versus host disease, HLA human leucocyte antigen, DLI Donor lymphocyte infusion, TBI total body Irradiation, HCT-CI hematopoietic cell transplantation-specific comorbidity index, INR international normalised ratio, $C M V$ cytomegalovirus, $E B V$ Epstein Barr virus, $S c r$ serum creatinine, $L D H$ lactate dehydrogenase, $e G F R$ estimated glomerular filtration rate, $H R$ hazard ratio, 95\% CI 95\% confidence interval. $* p<0.2$ in univariate analysis; $* * p 0.05$ in multivariate analysis. not the degree of platelet deficiency, may have a greater impact on the occurrence of DAH. DAH is increasingly postulated to be associated with EC damage [7, 11, 25, 35], and delayed platelet engraftment indicates a higher intensity of myelosuppression [36], which reflects the severity of EC damage to some extent [37]. Furthermore, a lower CD34+ dose has been shown to be associated with slower neutrophil engraftment and platelet engraftment [38, 39]. In our study, fewer CD34+ cells were infused in patients with
DAH than in those without DAH, although the infusion of fewer CD34+ cells did not remain significant in the multivariate analysis. We suspect that delayed platelet engraftment is an important and indispensable component of the pathogenesis of DAH. A more precise prospective study is required to confirm this hypothesis, which will help improve the management of allogenic HSCT recipients.

Severe acute GVHD, TMA, delayed neutrophil engraftment, myeloablative conditioning containing TBI and UCB 
HCT have also been reported as risk factors for DAH $[3,8,40,41]$. However, these factors were not considered risk factors for DAH in our study. In the univariate analysis, the incidences of grade III-IV aGVHD after allo-HSCT were indeed significantly higher in the DAH group than in the non-DAH group. Endothelial cell (EC) damage caused by GVHD may explain this effect [42]. Early identification of high-risk patients and the implementation of appropriate precautions are meaningful for this life-threatening complication of DAH. The association of DAH with TMA has been infrequently reported [41]. DAH and TMA are both postHSCT EC activation syndromes [11, 25, 35, 43]. Prolonged EC activation and damaging stimuli can lead to EC dysfunction, which is hypothesised to be critical in procoagulant, proinflammatory and proapoptotic responses that may result in early post-HCT complications [44]. The role of neutrophil extracellular traps (NETs) in the pathogenesis of TMA and DAH has also been elucidated in previous studies. NETs cooperate with the injured endothelium to promote thrombosis in small vessels, leading to haemolysis, thrombocytopenia, poor end-organ perfusion, and ultimately, TATMA [45]. Little is known about the role of NETs in HSCTassociated DAH. Jarrot et al. suggested a pathogenic role of polymorphonuclear neutrophils and NETs in lung injury during pristane-induced DAH [46].

The treatment for DAH is often lacking and inadequate, which leads to rapid deterioration and high mortality rates for patients. DAH treatment is usually tentative and practical, including general supportive care (such as fluid and sodium management and mechanical ventilation), adequate prophylactic antibiotics and systemic glucocorticoids, sometimes with ACA and recombinant activated factor VII $[3,4,8,10,12]$. We found that patients receiving a low dose of glucocorticoids presented a better prognosis than those receiving a high dose, while in multivariate analysis, no dose of glucocorticoids played a significant role in determining the prognosis of patients with DAH, consistent with previous studies $[3,4,8]$. Based on these findings, a limitation of our study is that patients who were perceived to be sicker at the time of DAH diagnosis might have inherently been placed on higher doses of steroids by their treating physicians. Prospective, randomised trials are needed to compare the effects of different doses of glucocorticoids to confirm the appropriate therapeutic dose. In clinical practice, when to use steroids and the dose of steroids to use in patients with immune deficiency after HSCT have become great challenges to clinical workers, which requires more clinical research to guide the specialists in making decisions. Intubation and the use of noninvasive ventilators did not affect the prognosis of patients with DAH, consistent with previous reports $[3,6]$ showing that respiratory failure, possibly due to diffuse lung injury, cannot be corrected with oxygen support.
The presence of coagulopathy was a risk factor for a poor prognosis of patients with DAH in our study. We showed that a high D-dimer level $(>500 \mathrm{ng} / \mathrm{ml})$ was a significant risk factor for a poor prognosis of patients with DAH. In previous studies, high blood levels of D-dimer and low levels of fibrinogen at the onset of transplantation-related complications were significantly associated with EC damage. [47-49] Elevated D-dimer levels appear to be related to acute lung injury [50]. In summary, elevated D-dimer levels might be caused by EC injuries in the pulmonary capillaries, reflecting the severity of endothelial injury in DAH, which may be a risk factor for the poor prognosis of patients with DAH after HSCT.

This study had deficiencies that cannot be ignored. The nature of retrospective nested case-control studies determines their lack of statistical efficiency compared to large cohort studies. In conclusion, we showed that DAH is very difficult to treat, the disease progresses rapidly, and few effective treatment options are available, leading to a very poor OS rate. Haploidentical transplantation performed similarly to matched related donor transplantation in terms of outcomes related to DAH. Delayed platelet engraftment was suggested to be a risk factor for the occurrence of DAH. High D-dimer levels $(>500 \mathrm{ng} / \mathrm{ml})$ were a significant risk factor for the poor prognosis of patients with DAH. Medium doses of glucocorticoids may exert a certain effect, but do not alter the extremely poor prognosis of patients with DAH. Multicentre prospective studies are needed to further investigate practical methods for prophylaxis for DAH and effective therapeutic strategies, thereby improving the prognosis of patients with DAH.

Acknowledgements This work was supported by the Beijing Municipal Science and Technology Commission (No. Z171100001017084), National Natural Science Foundation of China (Nos. 81970113, 81730004 and 81670116), Beijing Natural Science Foundation (Nos. H2018206423 and 7171013), the National Key Research and Development Program of China (Nos. 2017YFA0105500 and 2017YFA0105503), and the Foundation for Innovative Research Groups of the National Natural Science Foundation of China (No. 81621001).

Author contributions XHZ designed the study. JW collected the data and acted as the guarantor of the paper who was responsible for the integrity of the entire work from the beginning of the study to the publication of the paper. XL, XC and RYG collected the data. HXF, $\mathrm{YH}$, and XDM helped revise the paper. JW and HXL conducted the statistical analyses. CHY reviewed the imaging studies. HC, YHC, YJC, LPX, KYL, XJH and XHZ were the haematologists for the patients included in the study, conducted the pretransplantation evaluation, and treated the patients before and after haematopoietic stem cell transplantation.

\section{Compliance with ethical standards}

Conflict of interest The authors declare no competing interests. 
Publisher's note Springer Nature remains neutral with regard to jurisdictional claims in published maps and institutional affiliations.

\section{References}

1. Passweg JR, Baldomero H, Bader P, Bonini C, Duarte RF, Dufour $\mathrm{C}$, et al. Use of haploidentical stem cell transplantation continues to increase: the 2015 European Society for Blood and Marrow Transplant activity survey report. Bone Marrow Transpl. 2017;52:811-7.

2. Wang Y, Liu QF, Xu LP, Liu KY, Zhang XH, Ma X, et al. Haploidentical vs identical-sibling transplant for AML in remission: a multicenter, prospective study. Blood. 2015; 125:3956-62.

3. Keklik F, Alrawi EB, Cao Q, Bejanyan N, Rashidi A, Lazaryan A, et al. Diffuse alveolar hemorrhage is most often fatal and is affected by graft source, conditioning regimen toxicity, and engraftment kinetics. Haematologica. 2018;103:2109-15.

4. Rathi NK, Tanner AR, Dinh A, Dong W, Feng L, Ensor J, et al. Low-, medium- and high-dose steroids with or without aminocaproic acid in adult hematopoietic SCT patients with diffuse alveolar hemorrhage. Bone Marrow Transpl. 2015;50:420-6.

5. Mo XD, Xu LP, Liu DH, Zhang XH, Chen H, Chen YH, et al. High-dose cyclophosphamide therapy associated with diffuse alveolar hemorrhage after allogeneic hematopoietic stem cell transplantation. Respiration. 2013;86:453-61.

6. Afessa B, Tefferi A, Litzow MR, Peters SG. Outcome of diffuse alveolar hemorrhage in hematopoietic stem cell transplant recipients. Am J Respir Crit Care Med. 2002;166:1364-8.

7. Afessa B, Tefferi A, Litzow MR, Krowka MJ, Wylam ME, Peters SG. Diffuse alveolar hemorrhage in hematopoietic stem cell transplant recipients. Am J Respir Crit Care Med. 2002;166:641-5

8. Majhail NS, Parks K, Defor TE, Weisdorf DJ. Diffuse alveolar hemorrhage and infection-associated alveolar hemorrhage following hematopoietic stem cell transplantation: related and highrisk clinical syndromes. Biol Blood Marrow Transpl. 2006;12:1038-46.

9. Majhail NS, Parks K, Defor TE, Weisdorf DJ. Alveolar hemorrhage following allogeneic hematopoietic cell transplantation using reduced-intensity conditioning. Bone Marrow Transpl. 2006;38:765-8

10. Elinoff JM, Bagci U, Moriyama B, Dreiling JL, Foster B, Gormley NJ, et al. Recombinant human factor VIIa for alveolar hemorrhage following allogeneic stem cell transplantation. Biol Blood Marrow Transpl. 2014;20:969-78.

11. Ueda N, Chihara D, Kohno A, Tatekawa S, Ozeki K, Watamoto K, et al. Predictive value of circulating angiopoietin-2 for endothelial damage-related complications in allogeneic hematopoietic stem cell transplantation. Biol Blood Marrow Transpl. 2014;20:1335-40.

12. Wanko SO, Broadwater G, Folz RJ, Chao NJ. Diffuse alveolar hemorrhage: retrospective review of clinical outcome in allogeneic transplant recipients treated with aminocaproic acid. Biol Blood Marrow Transpl. 2006;12:949-53.

13. Wang Y, Fu HX, Liu DH, Xu LP, Zhang XH, Chang YJ, et al. Influence of two different doses of antithymocyte globulin in patients with standard-risk disease following haploidentical transplantation: a randomized trial. Bone Marrow Transpl. 2014;49:426-33.

14. Yan $\mathrm{CH}$, Wang $\mathrm{Y}$, Mo XD, Sun YQ, Wang FR, Fu HX et al. Incidence, risk factors, and outcomes of cytomegalovirus retinitis after haploidentical hematopoietic stem cell transplantation. Bone Marrow Transpl. 2020. e-pub ahead of print 2020/01/30; https:// doi.org/10.1038/s41409-020-0790-Z
15. Huang XJ, Liu DH, Liu KY, Xu LP, Chen H, Han W, et al. Haploidentical hematopoietic stem cell transplantation without in vitro T-cell depletion for the treatment of hematological malignancies. Bone Marrow Transpl. 2006;38:291-7.

16. Spira D, Wirths S, Skowronski F, Pintoffl J, Kaufmann S, Brodoefel $\mathrm{H}$, et al. Diffuse alveolar hemorrhage in patients with hematological malignancies: HRCT patterns of pulmonary involvement and disease course. Clin Imaging. 2013;37:680-6.

17. De Lassence A, Fleury-Feith J, Escudier E, Beaune J, Bernaudin JF, Cordonnier C. Alveolar hemorrhage. Diagnostic criteria and results in 194 immunocompromised hosts. Am J Respir Crit Care Med. 1995;151:157-63.

18. Ben-Abraham R, Paret G, Cohen R, Szold O, Cividalli G, Toren A, et al. Diffuse alveolar hemorrhage following allogeneic bone marrow transplantation in children. Chest. 2003;124:660-4.

19. Glucksberg H, Storb R, Fefer A, Buckner CD, Neiman PE, Clift RA, et al. Clinical manifestations of graft-versus-host disease in human recipients of marrow from HL-A-matched sibling donors. Transplantation. 1974;18:295-304.

20. Rowlings PA, Przepiorka D, Klein JP, Gale RP, Passweg JR, Henslee-Downey PJ, et al. IBMTR Severity Index for grading acute graft-versus-host disease: retrospective comparison with Glucksberg grade. Br J Haematol. 1997;97:855-64.

21. Przepiorka D, Weisdorf D, Martin P, Klingemann HG, Beatty P, Hows J, et al. 1994 Consensus Conference on Acute GVHD Grading. Bone Marrow Transpl. 1995;15:825-8. e-pub ahead of print 1995/06/01

22. Jagasia MH, Greinix HT, Arora M, Williams KM, Wolff D, Cowen EW, et al. National Institutes of Health Consensus Development Project on Criteria for Clinical Trials in Chronic Graft-versus-Host Disease: I. The 2014 Diagnosis and Staging Working Group report. Biol Blood Marrow Transpl. 2015;21:389-401 e381.

23. Nathan S, Ustun C. Complications of Stem Cell Transplantation that Affect Infections in Stem Cell Transplant Recipients, with Analogies to Patients with Hematologic Malignancies. Infect Dis Clin North Am. 2019;33:331-59.

24. Agusti C, Ramirez J, Picado C, Xaubet A, Carreras E, Ballester E, et al. Diffuse alveolar hemorrhage in allogeneic bone marrow transplantation. A postmortem study. Am J Respir Crit Care Med. 1995;151:1006-10.

25. Carreras E, Diaz-Ricart M. The role of the endothelium in the short-term complications of hematopoietic SCT. Bone Marrow Transpl. 2011;46:1495-502.

26. Nusair S, Breuer R, Shapira MY, Berkman N, Or R. Low incidence of pulmonary complications following nonmyeloablative stem cell transplantation. Eur Respir J. 2004;23:440-5.

27. Um SW, Choi CM, Lee CT, Kim YW, Han SK, Shim YS, et al. Prospective analysis of clinical characteristics and risk factors of postbronchoscopy fever. Chest. 2004;125:945-52.

28. Tulapurkar ME, Almutairy EA, Shah NG, He JR, Puche AC, Shapiro $\mathrm{P}$, et al. Febrile-range hyperthermia modifies endothelial and neutrophilic functions to promote extravasation. Am J Respir Cell Mol Biol. 2012;46:807-14.

29. Shenkar R, Abraham E. Mechanisms of lung neutrophil activation after hemorrhage or endotoxemia: roles of reactive oxygen intermediates, NF-kappa B, and cyclic AMP response element binding protein. J Immunol. 1999;163:954-62. e-pub ahead of print 1999/ $07 / 08$

30. Thomas AJ, Ascanio-Cortez L, Gomez S, Salem M, Maragkos G, Hanafy KA. Defining the Mechanism of Subarachnoid HemorrhageInduced Pyrexia. Neurotherapeutics. 2020;17:1160-9.

31. Saper CB, Romanovsky AA, Scammell TE. Neural circuitry engaged by prostaglandins during the sickness syndrome. Nat Neurosci. 2012;15:1088-95. 
32. Travassos LH, Vasconcellos LR, Bozza MT, Carneiro LA. Heme and iron induce protein aggregation. Autophagy. 2017;13:625-6.

33. Nash RA, Gooley T, Davis C, Appelbaum FR. The Problem of Thrombocytopenia after Hematopoietic Stem Cell Transplantation. Oncologist. 1996;1:371-80. e-pub ahead of print 1996/01/01

34. Robbins RA, Linder J, Stahl MG, Thompson AB 3rd, Haire W, Kessinger A, et al. Diffuse alveolar hemorrhage in autologous bone marrow transplant recipients. Am J Med. 1989;87:511-8.

35. Pagliuca S, Michonneau D, Sicre de Fontbrune F, Sutra Del Galy A, Xhaard A, Robin M, et al. Allogeneic reactivity-mediated endothelial cell complications after HSCT: a plea for consensual definitions. Blood Adv. 2019;3:2424-35.

36. Inbal A, Lubetsky A, Shimoni A, Dardik R, Sela BA, Eskaraev R, et al. Assessment of the coagulation profile in hemato-oncological patients receiving ATG-based conditioning treatment for allogeneic stem cell transplantation. Bone Marrow Transpl. 2004;34:459-63.

37. Cheuk DK, Wang P, Lee TL, Chiang AK, Ha SY, Lau YL, et al. Risk factors and mortality predictors of hepatic veno-occlusive disease after pediatric hematopoietic stem cell transplantation. Bone Marrow Transpl. 2007;40:935-44.

38. Remberger M, Torlen J, Ringden O, Engstrom M, Watz E, Uhlin $\mathrm{M}$, et al. Effect of Total Nucleated and CD34(+) Cell Dose on Outcome after Allogeneic Hematopoietic Stem Cell Transplantation. Biol Blood Marrow Transpl. 2015;21:889-93.

39. Chang YJ, Xu LP, Liu DH, Liu KY, Han W, Chen YH, et al. Platelet engraftment in patients with hematologic malignancies following unmanipulated haploidentical blood and marrow transplantation: effects of CD34+ cell dose and disease status. Biol Blood Marrow Transpl. 2009;15:632-8.

40. Wojno KJ, Vogelsang GB, Beschorner WE, Santos GW. Pulmonary hemorrhage as a cause of death in allogeneic bone marrow recipients with severe acute graft-versus-host disease. Transplantation. 1994;57:88-92.

41. Srivastava A, Gottlieb D, Bradstock KF. Diffuse alveolar haemorrhage associated with microangiopathy after allogeneic bone marrow transplantation. Bone Marrow Transpl. 1995;15:863-7. epub ahead of print 1995/06/01

42. Nassar AA. Haploidentical stem cell transplantation. Hematol Oncol Stem Cell Ther. 2012;5:73-83.

43. Jodele S, Laskin BL, Dandoy CE, Myers KC, El-Bietar J, Davies $\mathrm{SM}$, et al. A new paradigm: diagnosis and management of HSCTassociated thrombotic microangiopathy as multi-system endothelial injury. Blood Rev. 2015;29:191-204.

44. Hildebrandt GC, Chao N. Endothelial cell function and endothelial-related disorders following haematopoietic cell transplantation. Br J Haematol. 2020;190:508-19.

45. Arai Y, Yamashita K, Mizugishi K, Watanabe T, Sakamoto S, Kitano T, et al. Serum neutrophil extracellular trap levels predict thrombotic microangiopathy after allogeneic stem cell transplantation. Biol Blood Marrow Transpl. 2013;19:1683-9.

46. Jarrot PA, Tellier E, Plantureux L, Crescence L, Robert S, Chareyre C, et al. Neutrophil extracellular traps are associated with the pathogenesis of diffuse alveolar hemorrhage in murine lupus. J Autoimmun. 2019;100:120-30.

47. Tatekawa S, Kohno A, Ozeki K, Watamoto K, Ueda N, Yamaguchi Y, et al. A Novel Diagnostic and Prognostic Biomarker Panel for Endothelial Cell Damage-Related Complications in Allogeneic Transplantation. Biol Blood Marrow Transpl. 2016;22:1573-81.

48. Han Y, Zhu L, Sun A, Lu X, Hu L, Zhou L, et al. Alterations of hemostatic parameters in the early development of allogeneic hematopoietic stem cell transplantation-related complications. Ann Hematol. 2011;90:1201-8.

49. Van Leer C, Stutz M, Haeberli A, Geiser T. Urokinase plasminogen activator released by alveolar epithelial cells modulates alveolar epithelial repair in vitro. Thromb Haemost. 2005;94:1257-64.

50. Huang LT, Chou HC, Wang LF, Chen CM. Tissue plasminogen activator attenuates ventilator-induced lung injury in rats. Acta Pharmacol Sin. 2012;33:991-7. 